\title{
East-West Schools of Physics
}

\author{
W.O. Lock
}

(CERN) Geneva

Particle physicists have long been proud of their international collaboration, and increasingly the teams carrying out experiments at the world's major accelerator laboratories can look beyond national, as well as scientific, frontiers.

Two formal international organizations mirror this internationalism CERN, the European Laboratory for Particle Physics near Geneva, Switzerland, funded by 14 Western European nations; and the Joint Institute for Nuclear Research (JINR), at Dubna, near Moscow, grouping 11 socialist countries. A fine example of East-West collaboration is thus the regular CERN-JINR School of Physics which brings together young experimental postgraduate students from both sets of Member States at the beginning of their careers to meet each other in informal surroundings. The aim is to give them a good basis in theoretical high energy physics, which they often have too little time to study in the normal course of their work.

In line with its aim of promoting particle physics in European universities, education has always been an important part of CERN's programme, and the CERN-JINR School evolved naturally from earlier CERN Schools.

\section{The CERN Schools of Physics}

The first CERN Schools were held over 10 days in April 1962 and March 1963 near CERN and dealt with nuclear emulsion techniques at accelerators and more general theoretical and experimental physics. In view of their evident success, it was decided from 1964 to hold the Schools outside Switzerland and to extend the programme to two weeks, to cover bubble chamber as well as emulsion techniques and experiments.

The 1964 School took place at Herceg-Novi at the invitation of the Yugoslav Federal Nuclear Energy Commission. By the time of the 1965 School (Bad Kreuznach, Germany) any restriction imposed by experimental technique was removed and it became the declared purpose of the School to teach predominantly theoretical physics to young experimental physicists. At this time, more than twenty years ago, such Schools at a relatively elementary level were rare, while many of the smaller universities in the Member States did not have the staff to teach theoretical elementary particle physics to their experimental physics students. In order also to give each country the chance to participate more closely in the work of CERN it was decided that each year the School would be held in a different Member State. Thus in 1966 it was in the Netherlands (Noordwijk-aan-Zee), in 1967 in Sweden (Rattvik), in 1968 in Spain (El Escorial) and in 1969 again in Switzerland (Leysin). In each case the programme was established and the detailed arrangements made by a joint Organizing Committee consisting of representatives from CERN and from the Host Country, with the expenses being shared between the two sides. The length of the School was established as two weeks and emphasis was placed on a core programme of four or five main lecture courses on topical subjects by experts. Fees were limited to board and lodging.

\section{Origin of the Joint CERN-JINR Schools of Physics}

In October 1966 N.N. Bogolubov, then as now Director of the JINR visited CERN. In the course of discussions with the CERN Director-General of the time, B.P. Gregory, he proposed that CERN and JINR should organize a joint East-West "Seminar on Future Perspectives in High Energy Physics". Gregory agreed and the first seminar of what subsequently became a series (extended in 1969 to include the United States), was held in Riga, Latvia in June 1967. (It was this series which eventually led to the creation of the International Committee for Future Accelerators, ICFA - see Europhys. News 16 (1985) 6, 13.

The idea of a joint CERN-JINR summer school was first raised by Gregory at the Riga meeting and was favourably received by Bogolubov. More detailed discussions took place over the following two years and it was eventually agreed to hold the first Joint School in a country which was neither a Member State of CERN nor of JINR but with close links with both, namely Finland. Through the enthusiastic cooperation of K.V. Laurikainen of the University of Helsinki this new venture in East-West collaboration took place at Loma-Koli in North Karelia from 21 June to 5 July 1970 and was generally agreed to have been a great success. It was attended by 86 young physicists, 28 from JINR and its member countries. Both Gregory and Bogolubov spent some days in Loma-Koli and took the opportunity to discuss various aspects of the collaboration between their two institutes, including preliminary plans for the 1971 School, earlier agreed to be organized by JINR.

This second School was held at Varna in Bulgaria, and attracted 102 students. From then on it was decided to hold Joint Schools every second year, with a normal CERN School of Physics being held in the intervening years. A pattern was also established for the organization of the Joint Schools with a tripartite Organizing Committee set up in each case, consisting of representatives from the host country, from JINR and from CERN. This Committee normally meets three times to establish the scientific programme, choose the lecturers, select the students, and make all the detailed arrangements. As for the normal CERN Schools, locations rotate amongst different countries. The Schools organized primarily by CERN have been: 1973 Ebeltoft, Denmark; 1977 Nafplion Greece; 1981 Hanko, Finland and 1985 Urbino, Italy. Those primarily organized by JINR have been held in Alushta, Crimea, USSR in 1975; Dobogoko Hungary in 1979; Tabor, Czechoslovakia in 1983; and near Varna, Bulgaria in 1987. The 1989 joint School will be held in the Netherlands.

\section{Organization of the Joint Schools}

An important element in ensuring sufficient participation by students from the JINR Member States has been the financial arrangements, agreed in 1969 and since unchanged. With the School held in Western Europe, CERN pays living expenses for all the participants - students and lecturers - from JINR and from its Member Countries. Similarly, when the School is held in a JINR Member State, JINR covers living expenses for all participants from CERN and its Member States. Travel costs in each case are paid by the parent institutes. After one cycle of schools, East and 
West, the expenditure on each side is compared and any difference refunded in cash from one Organization to the other. In practice this system has worked very well and has allowed a substantial participation by physicists from the Dubna Member States in the Schools organized in Western Europe and vice-versa.

After many years experience, the concept of a core programme of five main lecture courses, usually of five lectures each, together with one or two subsidiary courses of two or three lectures each has been shown to be the approach most favoured and appreciated by the students. It enables them both to study a number of topics in some depth and to get to know the lecturers, chosen not only for their pedagogical skills but also for their ability to interact with the students. Since the format is the same for both normal CERN Schools and for the Joint Schools, the programme for the 1988 CERN School, held this month in Lefkada, Greece, is a good example. The main lecture courses will be: Introduction to Field Theory (J. Iliopoulos, Paris), Weak Interactions (G. Altarelli, CERN), Perturbative QCD (W.J. Stirling, Durham), Beyond the Standard Model (D.V. Nanopoulos, Wisconsin) and Collider Experiments (P. Jenni, CERN), while shorter courses will be on Heavy Ion Collisions (W. Willis, CERN), New Ideas in Detectors (T. Ypsilantis, Paris and UCLA), Particle Physics and Cosmology (G. Lazarides, Thessaloniki). CERN's research programme will be described by CERN Director-General H. Schopper and there will also be a talk on physics in Greece. At a Joint School descriptions would also be given of the research programme at JINR Dubna and at the Institute for High Energy Physics (IHEP) Serpukhov.

A second important feature, again the result of years of valuable experience, is the choice of discussion leaders for

\section{University of Lund Division of Cosmic and Sub atomic Physics Postdoctoral Research Fellowship in Heavy Ion Physics}

Applications are invited for a position as a postdoctoral research fellow in experimental heavy ion physics, funded by a grant from the Swedish Natural Science Research Council (NFR) for a period of one year and renewable for a second year. The successful candidate will be expected to pursue research within an international collaboration and to be mainly involved in the construction and the analysis of experiments at the Celsius storage ring in Uppsala and at French accelerator laboratories.

The research fellow will be stationed at the Division of Cosmic and Subatomic Physics, University of Lund and receive a tax-free salary in the range of 8000-9000 SKR per month.

The application together with a curriculum vitae and major publications should be sent not later than 15 October 1988 to the Administrative Head:

Bengt Roman - Department of Physics - Soelvegatan 14 - S - 22362 LUND, Sweden

For further information please contact:

Docent Bo Jakobsson, Division of Cosmic and Subatomic Physics,

University of Lund, Soelvegatan 14, S - 22362 LUND, Sweden

Tel.: +46 (46) $107708 \quad$ Telefax: $+46(46) 104709$

Telex: 33533 luniver s Bitnet "kosubo seldc51"

afternoon sessions on questions arising from the lecture courses. These discussion leaders are usually young theoretical physicists who frequently go on to become lecturers at Schools in later years. At Varna, 1987, for example, there were seven discussion leaders two from Bulgaria, two from JINR, and one each from CERN, the University of Crete and the University of Leiden.

All students are encouraged to bring with them material illustrating the experiments on which they are working. This is displayed at a special poster session early in the programme in a relaxed atmosphere.

The location of a School with recreational facilities at hand is also important, not to mention decent weather and good food and drink at a reasonable price, and it can be tricky to take all requirements into consideration. $A$ hotel just large enough to take all participants with a good lecture room and smaller rooms for discussion sessions, set in a small village or town with not too many distractions, is ideal. Schools have been held in isolated places or on small islands (such as that at Sandhamn in the Swedish archipelago in 1986).

\section{Joint School}

The 1989 Joint CERN-JINR School of Physics, the eleventh in the series since 1970 , will be held in the small seaside resort of Egmond-aan-Zee on the North Sea coast of the Netherlands, some 50 $\mathrm{km}$ north of Amsterdam, from 25 June8 July 1989 . The scientific programme will be announced in October when Bulletin No. 1 will be widely distributed in the twenty-five Member States of CERN and of JINR as well as in some non-Member States such as Finland, which has twice hosted a Joint School. Students interested in participating in the 1989 School may obtain more information from:

Ms. S.M. Tracy at CERN (Telex $419000 \mathrm{cer}$ ch, Fax 022 / 8375 55, Tel. 022 / 8327 24; Electronic Mail (EARN/BITNET) Tracy at CERNVM, or from Mrs. T.S. Donskova, International Department at JINR (Head Post Office, P. O. Box 79, 101000 Moscow, Telex 412621 dubna su, Tel. 9262251 ).

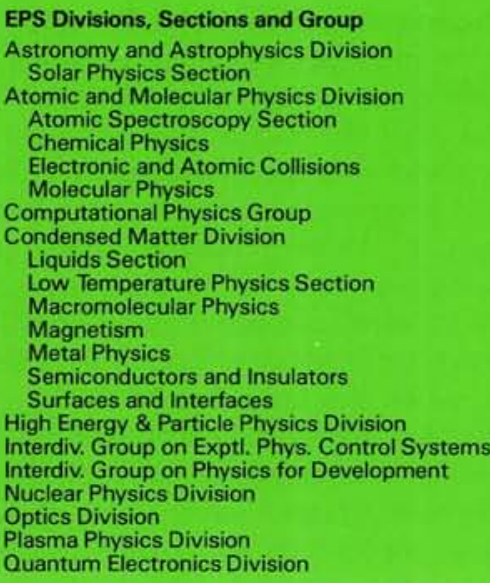

Europhysics News is the official journal of the European Physical Society which comprises 29 National Societies, Academies and Group, about 4000 Individual Members and 75 Associate Members. Governing bodies of EPS are the General Meeting, Council and an elected Executive Committee responsible for detailed policy. EPS promotes the collaboration of physicists throughout Europe, organising and harmonising conferences and publications, improving physics education, encouraging physics applications, awarding scholarships to sponsored schools in Erice. EPS publishes in addition to Europhys. News, Europhysics Letters (in addition to Europhys. News, Europhysics Letters (in partnership with national societies), European Journal
of Physics (in partnership with The UK Inst. of Phys.), and European Conference Abstracts. Individual Members receive Europhys. News free of charge (price to insts.: Sw.Fr. 90.-la), Europhys. Lett. at Sw.Fr. 125.-/a (insts. 1050.-), rebates on many other publications and on conference fees. Annual EPS membership fee for inon conference fees. Annual EPS membership fee for inis: Sw.Fr. 44.-; independent members: Sw.Fr. 132. members of a Collaborating Society: Sw.Fr. 55 .-

\section{Editor: E.N. Shaw \\ Editorial Board: \\ A. Baratoff, F. James, M. Lehmann, \\ M. Mayor, J. Muller, M. Siegrist}

Editorial and Advertising Office at the EPS Secretariat

Address: EUROPEAN PHYSICAL SOCIETY

P. O. Box 69

$\mathrm{CH}-1213$ Petit-Lancy 2

Switzerland

Telephone: Geneva (22) 931130

Telex: 428024 eps ch

Telefax: (22) 931317

Printed by: Pfirter frères sa CH-1213 Petit-Lancy/Switzerland 